\title{
Absceso perianal recidivante como presentación clínica de leiomioma de canal anal
}

\author{
Recurrent perianal abscess as clinical presentation \\ of anal canal leiomyoma
}

Natalia Gutiérrez C. ${ }^{1}$, Guillermo Carreño V. ${ }^{1}$, María Fernández H. ${ }^{2}$ y Nuria Aguado S. ${ }^{2}$

Mujer de 62 años sin antecedentes de interés que acude por tumoración perianal dolorosa de 4 semanas de evolución con empeoramiento progresivo. La exploración física es compatible con absceso perianal y se realiza drenaje quirúrgico con evolución favorable.

A los 2 meses, misma sintomatología objetivándose tumoración con signos de flogosis, pero sin salida de material purulento tras exploración quirúrgica. Se solicita resonancia pélvica en la que se halla una masa heterogénea que se origina en canal anal de 55 por $48 \mathrm{~mm}$, que se extiende por el espacio perineal posterior en contacto con la vertiente posterolateral del músculo puborrectal (Figuras la y 1b).
Tras confirmación histólogica de leiomioma mediante PAAF ecoguiada, la paciente es intervenida a través de un abordaje combinado perineal posterior e interesfinteriano, realizándose exéresis completa de la lesión (Figura 2). Tras un año de seguimiento, no existen signos clínicos ni radiológicos de recidiva.

La forma de presentación como absceso perianal recidivante y la baja incidencia del leiomioma a nivel rectal $(<0,1 \%)$ hace difícil una sospecha diagnóstica inicial ${ }^{1}$. Además, es necesario un seguimiento a largo plazo debido al riesgo de recidivas de hasta un $40 \%$, pudieno llegar hasta $10 \%$ en forma de leiomiosarcomas ${ }^{2,3}$.

\author{
'Hospital Universitario San \\ Agustín. Avilés. \\ ${ }^{2}$ Hospital Universitario Central \\ de Asturias. Oviedo. \\ Asturias, España. \\ Recibido el 28 de febrero \\ de 2019 y aceptado para \\ publicación el 23 de abril de \\ 2019
}

Correspondencia a: Dra. Natalia Gutiérrez $C$ ngcorral@hotmail.com
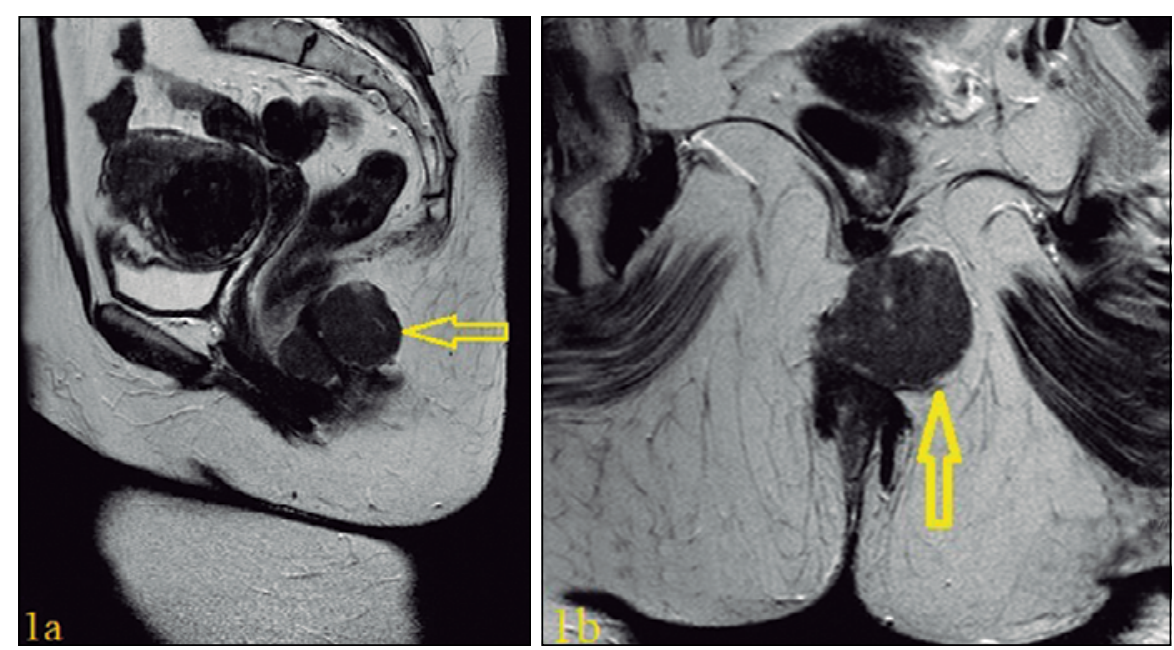

Figura 1. a: RNM pelvis corte sagital. b: RNM pelvis corte coronal. Masa que se origina en el canal anal, en su aspecto más inferior y posterior, heterogénea, sólida, mamelonada de 55 x 48 mm invadiendo espacio puboanal, con afectación del músculo puborrectal y esfínter externo (flechas).

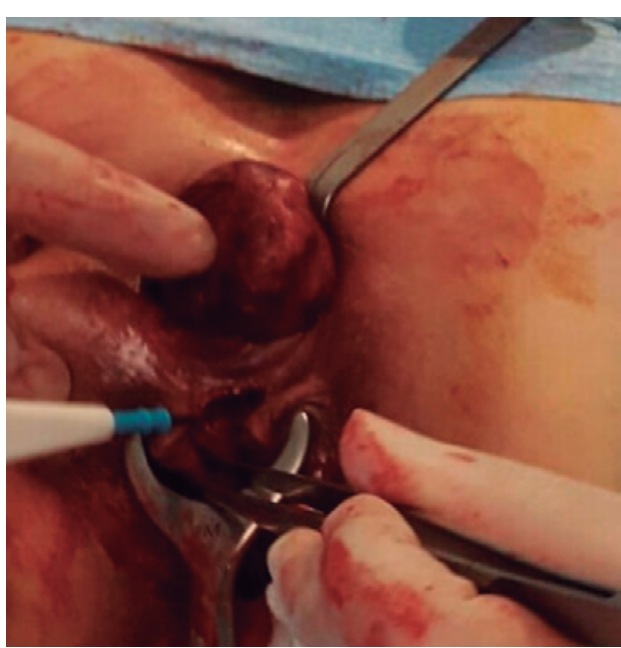

Figura 2. Cirugía del leiomioma. Posición de jack-knife Abordaje combinado perineal posterior e interesfisteriano, realizándose exéresis completa de la lesión. 


\section{Responsabilidades éticas}

Protección de personas y animales. Los autores declaran que para esta investigación no se han realizado experimentos en seres humanos ni en animales.
Confidencialidad de los datos. Los autores declaran que en este artículo no aparecen datos de pacientes.

Conflictos de interés: no hay.

\section{Bibliografía}

1. Sunkara T, Then EO, Culliford A, Gadupiti V. Rectal leiomyoma, a rare entity. Clin Pract. 2018;8:1053. doi: 10.4081/cp.2018.1053.
2. García-Santos EP, Ruescas-García FJ, Estaire-Gómez M, Martín-Fernández J, González-López L. Anorectal leiomyoma: a case report and literature review. Rev Gastroenterol Mex. 2014;79:58-60. doi: 10.1016/j.rgmx.2013.05.002.
3. Núñez Martínez O, Salinas Moreno S, Manceñido Marcos N, Pajares Villarroya R, Erdozaín Sosa JC. Rectal leiomyoma: endoscopic resection. Gastroenterol Hepatol. 2012;35:373-5. doi: 10.1016/j. gastrohep.2011.12.007. 